\title{
Prevalence of Occupational Allergic Diseases in Workers Involved in Animal Production
}

\author{
Vanessa Mateus $^{1 *}$, Elisabete Carolino ${ }^{1}$, Carla Viegas ${ }^{1,2}$ and Susana Viegas ${ }^{1,2}$ \\ ${ }^{1}$ H\&TRC - Health and Technology Research Center, ESTeSL - Lisbon School of Health Technology, Instituto Politecnico \\ de Lisboa, Lisboa, Portugal; vanessa.mateus@estesl.ipl.pt \\ ${ }^{2}$ Centro de Investigação em Saude Publica, Escola Nacional de Saude Publica, Universidade NOVA \\ de Lisboa, Lisboa, Portugal
}

\begin{abstract}
Background: Working in swine and poultry farms is described as a harmful job to the workers, because it has been shown that is capable of leading to occupational asthma and other allergic diseases. Objective: The main objective of this study is the epidemiological characterization of occupational allergic diseases in swine and poultry Portuguese farms. Methods: About 37 (46.3\%) workers from 7 swine and 43 (53.7\%) from 7 poultry farms participated in this study. The data was collected through a questionnaire the European Community Respiratory Health Survey under the form of interview. Results: The prevalence of asthma was $10 \%$. About $50.0 \%$ of the asthmatics had occupational asthma and $37.5 \%$ had work-aggravated asthma. Among non-asthmatic workers, it was reported wheezing associated with dyspnea (5.6\%), dyspnea after strenuous activity (11.1\%) and persistent cough (23.6\%). The prevalence of allergic rhinitis was $20 \%$, of which $56.2 \%$ of the cases had the $1^{\text {st }}$ crisis after the beginning of work on farms. Among workers without medical diagnosis of rhinitis, $21.9 \%$ reported the presence of sneezing, rhinorrhea or nasal congestion without being constipated. There were skin allergies in $31.2 \%$ of the farmers, of which $72 \%$ were work-related symptoms. Conclusions: Findings of this study suggest that these farms develop activities that promote contact with harmful agents with influence on workers' health and their workers completely devalue the disease symptoms they present.
\end{abstract}

Keywords: Hypersensitivity, Public Health, Occupational Medicine, Occupational Exposure

\section{Introduction}

Working in animal production has been described as detrimental to the workers' health, because it has been shown that is capable of leading to occupational asthma and other allergic diseases ${ }^{1,2}$. Cases of respiratory symptoms, including cough, expectoration and chest tightness or even diseases like asthma, rhinitis and other allergic diseases, have been identified in both type of animal production as a result of occupational exposure ${ }^{1-4}$. More specifically, there have been reported an increased prevalence of several respiratory symptoms and diseases, such as chronic bronchitis, chronic obstructive pulmonary disease and organic dust toxic syndrome ${ }^{5-9}$. Regarding some specific settings, such as poultry and swine farms, have not been reported a complete characterization of prevalence of occupational allergic diseases and work-related symptoms without diagnosis. This lack increases the devaluation of the health consequences of their work and can constitute a barrier for the implementation of preventive interventions.

Asthma is a chronic inflammatory disease of the airways with recurrent episodes of wheezing, dyspnea, chest tightness and cough ${ }^{10}$. Usually, it is associated with generalized and variable airway obstruction, which can be reversed spontaneously or through pharmacological therapy ${ }^{10}$. In this professional context, occupational asthma may develop, when the specific occupational environment is responsible for the onset of the disease; or asthma can be aggravated at the workplace, when a pre-existing asthmatic condition is aggravated by occupational exposure ${ }^{11}$. The prevalence of occupational asthma ranges from 5\% to $10 \%$ in the European asthmatic population ${ }^{12,13}$.

Work practices such as the use of specific bedding material, the types and methods of animal feeding, and the use of some specific disinfectants have also been related to workers' symptoms ${ }^{14,15}$. Organic dust particles become

*Author for correspondence 
aerosolized for a long time or deposited on the floor when feeding occurs ${ }^{16}$. Thus, high dispersion of microorganisms and their metabolites occurs as they are re-suspended during this task ${ }^{17,18}$. The particulate matter in the generated organic dust varies in composition, size and density, and these characteristics may influence the workers' health due to aerosolization and bioaerosol contamination ${ }^{19}$. The main objective of this study is the epidemiological characterization of occupational allergic diseases in swine and poultry Portuguese farms.

\section{Methods}

Descriptive cross-sectional study. The sample is constituted for workers from 7 swine and 7 poultry Portuguese farms, selected for convenience.

\subsection{Questionnaire}

People working in the swine and poultry farms were interviewed through the European Community Respiratory Health Survey (ECRHS Questionnaire) validated for Portuguese population, used for the examination of workrelated symptoms ${ }^{12}$.

\subsection{Statistical Analysis}

Statistical Package for Social Sciences (SPSS) version 19 was used for the statistical treatment. A simple descriptiveanalysis was carried out for the socio-demographic characterization, the presence of asthma and other allergic diseases, the existence of respiratory symptomatology and allergy in the sample and its influence on professional performance. The chi-square test and the odds ratio were used to evaluate, respectively, the relationship of independence and the risk between respiratory symptomatology and the presence of asthma in workers. The $\mathrm{p}<0.05$ level was considered significant.

\section{Results}

\subsection{Socio-demographic Characteristics}

The study included 80 workers, of whom 43 (53.7\%) worked in poultry and $37(46.3 \%)$ in swine farms. The population is $60 \%$ men and the mean age is $42.7 \pm 11.8$ years, which had mostly between 31 and 58 years (76.2\%). Workers, on average, work on farms for about $13.6 \pm 10.9$ years (Table 1 ).

\subsection{Prevalence of Asthma}

The prevalence of asthma was $10 \%(\mathrm{n}=8)$, belonging mainly to the female gender $(n=5,62.5 \%)$. Mostly of these workers works in swine farms $(\mathrm{n}=6,75.0 \%)$ (Table 1). Among asthmatic workers, 4 (50.0\%) reported their first asthmatic crisis after having started their profession on farms (Table 2) and others 3(37.5\%) reported asthma aggravated in the workplace. All asthmatic workers report an improvement in respiratory symptomatology during the weekend.

Table 1. Socio-demographic distribution of the population, depending on the presence or absence of asthma

\begin{tabular}{|r|c|c|c|}
\hline \multirow{2}{*}{} & \multirow{2}{*}{ Total n (\%) } & \multicolumn{2}{|c|}{ Asthma } \\
\cline { 3 - 4 } & \multirow{2}{*}{ Number of individuals } & Presence n (\%) & $72(90.0 \%)$ \\
\cline { 3 - 4 } & & $8(10 \%)$ & $72(100 \%)$ \\
\cline { 3 - 4 } Age & & $8(100 \%)$ & $7(9.7 \%)$ \\
\hline$[17 ; 24]$ & $7(8.7 \%)$ & $0(0.0 \%)$ & $8(11.1 \%)$ \\
\hline$[24 ; 31]$ & $9(11.3 \%)$ & $1(12.5 \%)$ & $11(15.3 \%)$ \\
\hline$[31 ; 38]$ & $12(15.0 \%)$ & $1(12.5 \%)$ & $15(20.8 \%)$ \\
\hline$[38 ; 45]$ & $15(18.7 \%)$ & $0(0.0 \%)$ & $18(25.0 \%)$ \\
\hline$[45 ; 52]$ & $21(26.2 \%)$ & $3(37.5 \%)$ & $11(15.3 \%)$ \\
\hline$[52 ; 59]$ & $13(16.3 \%)$ & $2(25.0 \%)$ & $1(1.4 \%)$ \\
\hline$[59 ; 66]$ & $2(2.5 \%)$ & $1(12.5 \%)$ & $45(62.5 \%)$ \\
\hline$[66 ; 73]$ & $1(1.3 \%)$ & $0(0.0 \%)$ & $27(37.5 \%)$ \\
\hline Masculino & & & \\
\hline Feminino & $38(60.0 \%)$ & $3(37.5 \%)$ & $41(56.9 \%)$ \\
\hline Gender & & $5(62.5 \%)$ & $31(43.1 \%)$ \\
\hline Poultry farm & $43(53.7 \%)$ & & \\
\hline Swine farm & $37(46.3 \%)$ & $2(25.0 \%)$ & \\
\hline Animal production & & $6(75.0 \%)$ & \\
\hline
\end{tabular}




\subsection{Respiratory Symptoms}

In the asthmatic population about $6(75.0 \%)$ were not controlled, namely $5(62.5 \%)$ reported wheezing associated with dyspnea, $5(62.5 \%)$ dyspnea at rest, $6(75.0 \%)$ dyspnea after strenuous activity, and $5(62.5 \%)$ persistent cough. However, the workers without medical diagnosis of asthma also reported the presence of respiratory symptoms $(n=29$, $39.7 \%)$, like wheezing $(\mathrm{n}=19,26.4 \%, \mathrm{p}<0.01)$, wheezing associated with dyspnea $(\mathrm{n}=4,5.6 \%, \mathrm{p}<0.01)$, dyspnea at rest $(\mathrm{n}=1,1.4 \%, \mathrm{p}<0.0001)$, dyspnea after strenuous activity $(\mathrm{n}=8,11.1 \%, \mathrm{p}<0.0001)$ and persistent cough $(\mathrm{n}=17$, $23.6 \%, \mathrm{p}<0.05$ ) (Table 2).

Table 2. Distribution of respiratory symptoms and age of $1^{\text {st }}$ asthmatic crisis according to the presence or absence of asthma

\begin{tabular}{|c|c|c|c|c|}
\hline & \multirow{2}{*}{ Total n (\%) } & \multicolumn{2}{|c|}{ Asthma } & \multirow{2}{*}{ p-value } \\
\hline & & Presence n (\%) & Absence n (\%) & \\
\hline \multirow[t]{2}{*}{ Number of individuals } & \multirow{2}{*}{$80(100 \%)$} & $8(10 \%)$ & $72(90 \%)$ & \multirow{2}{*}{--} \\
\hline & & $8(100 \%)$ & $72(100 \%)$ & \\
\hline \multicolumn{4}{|l|}{ Age of 1st asthmatic crisis } & \multirow{5}{*}{--} \\
\hline$[1 ; 15]$ & -- & $4(50.0 \%)$ & -- & \\
\hline$[15 ; 30]$ & -- & $0(0.0 \%)$ & -- & \\
\hline$[30 ; 45]$ & -- & $1(12.5 \%)$ & -- & \\
\hline$[45 ; 60]$ & -- & $3(37.5 \%)$ & -- & \\
\hline \multicolumn{4}{|l|}{ Wheezing } & \multirow{3}{*}{$0.005^{* x}$} \\
\hline Yes & $25(31.2 \%)$ & $6(75 \%)$ & $19(26.4 \%)$ & \\
\hline No & $55(68.8 \%)$ & $2(25 \%)$ & $53(73.6 \%)$ & \\
\hline \multicolumn{4}{|l|}{ Wheezing with dyspnea } & \multirow{3}{*}{$0.006^{* x}$} \\
\hline Yes & $9(11.2 \%)$ & $5(62.5 \%)$ & $4(5.6 \%)$ & \\
\hline No & $16(20.0 \%)$ & $1(12.5 \%)$ & $15(20.8 \%)$ & \\
\hline \multicolumn{4}{|l|}{ Dyspnea at rest } & \multirow{3}{*}{$0.000^{* *}$} \\
\hline Yes & $6(7.5 \%)$ & $5(62.5 \%)$ & $1(1.4 \%)$ & \\
\hline No & $74(92.5 \%)$ & $3(37.5 \%)$ & $71(98.6 \%)$ & \\
\hline \multicolumn{4}{|l|}{ Dyspnea after strenuous activity } & \multirow{3}{*}{$0.000^{* * x}$} \\
\hline $\begin{array}{ll}\text { Yes } \\
\end{array}$ & $14(17.5 \%)$ & $6(75.0 \%)$ & $8(11.1 \%)$ & \\
\hline No & $66(82.5 \%)$ & $2(25.0 \%)$ & $64(88.9 \%)$ & \\
\hline \multicolumn{4}{|l|}{ Waking up with dyspnea crisis } & \multirow{3}{*}{$0.000^{* *}$} \\
\hline $\begin{array}{lr} & \text { Yes } \\
\end{array}$ & $7(8.7 \%)$ & $4(50.0 \%)$ & $3(4.2 \%)$ & \\
\hline No & $73(91.3 \%)$ & $4(50.0 \%)$ & $69(95.8 \%)$ & \\
\hline \multicolumn{4}{|l|}{ Persistent cough } & \multirow{3}{*}{$0.019^{*}$} \\
\hline Yes & $22(27.5 \%)$ & $5(62.5 \%)$ & $17(23.6 \%)$ & \\
\hline No & $58(72.5 \%)$ & $3(37.5 \%)$ & $55(76.4 \%)$ & \\
\hline
\end{tabular}

Legend: Qui-square test; * - significant for $\mathrm{p}<0.05 ; * *$ - significant for $\mathrm{p}<0.01 ; * * *$ - significant for $\mathrm{p}<0.001$.

The results of the statistical analysis was performed to measure the risk between the presence of respiratory symptoms and the presence of asthma revealing that dyspnea at rest was the symptom with the highest associated risk $(\mathrm{OR}=118.3[10.3-1355.0])$. Other symptoms were also associated with a higher risk factor, such as dyspnea after strenuous physical activity $(\mathrm{OR}=24.0[4.1-139.6])$, waking up with dyspnea crisis $(\mathrm{OR}=23.0$ [3.7-139.8]) and wheezing associated with dyspnea $(\mathrm{OR}=18.7$ [1.6-209.5]) (Table 3). 
Table 3. Risk of developing asthma according to the respiratory symptomatology presented

\begin{tabular}{|l|c|}
\hline & Asthma \\
\hline & OR (CI 95\%) \\
\hline Wheezing & $8.3(1.5-45.0)$ \\
\hline Wheezing with dyspnea & $18.7(1.6-209.5)$ \\
\hline Dyspnea at rest & $118.3(10.3-1355.0)$ \\
\hline Dyspnea after strenuous activity & $24.0(4.1-139.6)$ \\
\hline Waking up with dyspnea crisis & $23.0(3.7-139.8)$ \\
\hline Persistent cough & $5.3(1.1-24.9)$ \\
\hline
\end{tabular}

Legend: OR - interval. odds ratio; CI - confidence

Regarding tobacco consumption, about 43 (53.7\%) of the workers are active smokers. Of the non-smokers, $16(43.2 \%)$ reported being regularly exposed to tobacco smoke. Among asthmatics, $4(57.1 \%)$ are active smokers and $2(66.6 \%)$ of the non-smokers reported being regularly exposed to tobacco smoke.

\subsection{Other Allergic Symptoms}

The prevalence of allergic rhinitis is $20 \%(n=16)$, of which $9(56.2 \%)$ had their first episode of rhinitis after starting their profession on farms. Of the individuals with allergic rhinitis, 15 (93.7\%) reported sneezing, runny nose or nasal congestion without being constipated or with influenza in the last year. However, it was also verified the presence of allergic symptoms in workers without allergic rhinitis ( $n=14,21.9 \%)$, which all of them reported the presence of sneezing, rhinorrhea or nasal congestion without being constipated $(p<0.0001)$ and some reported the presence of sneezing associated with weep $(\mathrm{n}=2,14.3 \%, \mathrm{p}<0.05)$. In this study, there were 3 workers $(37.5 \%)$ with allergic rhinitis and asthma, simultaneously.

Skin allergy is manifested in $25(31.2 \%)$ workers, of which $18(72 \%)$ associate this allergy with the farm work, with one or more activities responsible for the triggering of allergy in each individual (Figure 1). Of the workers with skin allergy, $15(60 \%)$ work in swine farms.

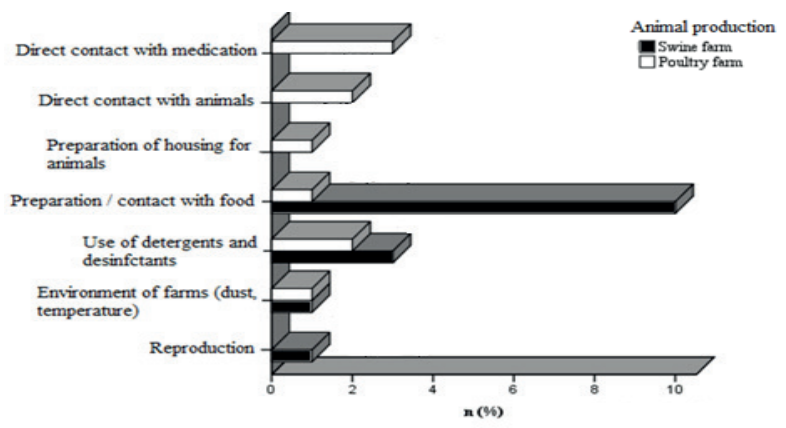

Figure 1. Distribution of the causes of skin allergies reported by the workers according to the animal production.

\subsection{Pharmacological Therapy}

Regarding the medications used, the asthmatic patients presented pharmacological therapy, of which about $3(42.8 \%)$ had an incorrect use of the drug (Table 4). The errors relate to the use of glucocorticoids in the control of intermittent asthmatic crises or the administration of Long-acting $\beta_{2}$ Adrenergic Agonists (LABA) alone as monotherapy. All drugs were administered by inhalation using unidose dry powder inhalers $1(14.3 \%)$, multidose dry powder inhalers $4(57.1 \%)$ and pressurized inhalers 2 (28.6\%). No pharmacological therapy was instituted for the other identified allergic diseases, like rhinitis and skin allergy.

Table 4. Pharmacotherapy used by asthmatic workers

\begin{tabular}{|c|c|c|}
\hline \multirow{2}{*}{$\begin{array}{l}\text { THERAPEUTIC } \\
\text { INDICATION }\end{array}$} & \multirow{2}{*}{$\begin{array}{c}\text { PHARMACO } \\
\text { THERAPEUTIC } \\
\text { CLASS } \\
\end{array}$} & N (\%) \\
\hline & & $7(100 \%)$ \\
\hline Daily & $\begin{array}{c}\text { Glucocorticoid + } \\
\text { LABA }\end{array}$ & $2(28.6 \%)$ \\
\hline \multirow{2}{*}{$\begin{array}{l}\text { Control of } \\
\text { asthmatic crises }\end{array}$} & SABA & $2(28.6 \%)$ \\
\hline & $\begin{array}{c}\text { Glucocorticoid + } \\
\text { LABA }\end{array}$ & $2(28.6 \%)$ \\
\hline $\begin{array}{l}\text { Periods of } \\
\text { greatest } \\
\text { exacerbation }\end{array}$ & $\begin{array}{l}\text { LABA in } \\
\text { monotherapy }\end{array}$ & $1(14.2 \%)$ \\
\hline
\end{tabular}

Legend: SABA - short-acting $\beta 2$ adrenergic agonist; LABA long-acting $\beta 2$ adrenergic agonists.

\subsection{Impact on Professional Performance}

The presence of asthma, dyspnea and/or wheezing is responsible for not attending the work of $10(12.5 \%$, $\mathrm{p}<0.05)$ workers in this study. In addition, some workers reported having spent one night in the hospital last year, due to respiratory problems such as asthma, pulmonary infection, chronic obstructive pulmonary disease or sinusitis $(\mathrm{n}=4.5 \%, \mathrm{p}<0.01)$.

Approximately $12(15 \%)$ workers showed episodes of chest tightness or wheezing in the course of their professional activity and $26(32.5 \%)$ reported an improvement in respiratory complications during the weekend.

\section{Discussion}

The prevalence of asthma in these two settings was $10 \%$, which is a slightly higher than the 6\% obtained in a prospective study carried out in Portugal for the general population $^{20}$. There is a higher prevalence of asthma in female subjects (in a predominantly male population), which may be explained by the fact that women have a lower airway diameter than men in adulthood. Furthermore, hormonal levels are another critical point, since estrogens 
demonstrate a reduction in airway hyper-reactivity, so the decrease of estrogens levels, in the luteal phase of the menstrual cycle and in menopause, aggravate asthma symptoms ${ }^{21,22}$. Mostly of these asthmatic women work in swine farms, suggesting a higher risk of developing asthma in these farms compared to professional activity in poultry farms, which is also supported by other studies ${ }^{1}$. This featured is probably justified by the fact that swine workers spend more time inside the pavilions than the poultry workers due to the specificity of tasks that need to be developed constantly such as castrating, ear tagging and teeth cutting, as well as activities related to feeding, floor sweeping and removal of dry manure ${ }^{23}$.

Regarding occupational asthma, 50\% of workers manifested their first asthmatic crisis after have started to work in these farms, suggesting that their professional activity may have been the trigger for the disease. The prevalence of occupational asthma on these farms of about $5 \%$ is at the minimum level of European studies $(5-10 \%)^{12,13}$. However, this study covered a specific occupational settings, unlike the European study in which different occupational settings were analyzed. The remaining asthmatics had asthma since the childhood, which sometimes has a tendency to regress in the adulthood, however continued exposure to some triggering factors may have aggravated the disease, with a consequent manifestation of respiratory symptoms. Microbial agents and particles in the air of animal production settings, such as poultry or swine farms, promote an increase of the occurrence of work-related symptoms in exposed workers ${ }^{24}$. Indeed, exposure assessment to these risk factors have already been demonstrated in a previous research work developed in the same swine and poultry units $^{25,26}$. These data possibly indicate that the continued exposure to high concentrations of fungi and particulate matter promotes an increase of the prevalence of asthma, as well as a worsening of the disease.

In asthmatic and non-asthmatic workers, the respiratory symptoms most frequently found were dyspnea after strenuous activity and persistent cough. Furthermore, it was also reported wheezing associated with dyspnea and dyspnea at rest in a high prevalence. The data are supported by the literature showing a high prevalence of wheezing and cough in poultry farmers and of work-related dyspnea, wheezing and coughing in swine farmers during their professional activities ${ }^{1,4}$. The respiratory symptoms constitute a risk factor for the onset or worsening of asthma ${ }^{10}$. Our study identified some symptoms with a high risk, like dyspnea after strenuous physical activity, morning dyspnea crisis and wheezing associated with dyspnea, but mainly dyspnea at rest, in which workers with this symptom present 118.33 times greater possibility of being asthmatic. The respiratory symptoms reported by non-asthmatic workers suggest the existence of asthmatic individuals without medical diagnosis, evidenced a devaluation of the harmful effects on health due to the continuous exposure to fungi and particulate matter. So, the prevalence of occupational asthma may be underestimated in these settings, since non-diagnosed farmers with respiratory and other allergic symptoms from occupational exposure were identified.

Since the respiratory symptoms can be aggravated by the tobacco consumption, our study pretended to evaluate the prevalence of active and non-active smokers or non-smokers. In the asthmatic workers, almost all are active or non-active smokers, promoting thus a favorable environment to aggravate its health condition ${ }^{10}$. That may translate into an increase in asthma exacerbations compared to non-smokers and, therefore, a negative influence of smoking on asthma control, accelerating the loss of function pulmonary and worsening the patient's quality of life ${ }^{13,27,28}$.

In our study, the prevalence of allergic rhinitis (20\%) in asthmatic workers is the expected, since the literature indicates $17 \%$ to $28.5 \%^{29}$. However, there are $21.9 \%$ of workers with sneezing, runny nose or nasal congestion without being flu and without medical diagnostic of allergic rhinitis. The devaluation of the symptoms of allergic rhinitis by the workers may be the origin of an underestimation of the prevalence of allergic rhinitis. Rhinitis is one of the most common respiratory disorders on farms, and this occupational activity is currently associated with increased nasal symptoms $\mathrm{s}^{30}$. In addition, rhinitis is a risk factor for the development of asthma ${ }^{31}$. Of the workers with allergic rhinitis, 93.7\% reported sneezing, rhinorrhea or nasal congestion without being flu, suggesting that the disease is not controlled ${ }^{29}$.

Of the workers with skin allergies, $72 \%$ associate this allergy to work, suggesting that these farms develop activities that promote contact with harmful agents with influence on workers' health ${ }^{1,2}$. The handling of flours used in animal feed is the most referred activity as the cause for the onset of skin allergies.

These data are already really worrisome, but may still be under-valued explained by the known "healthy worker effect". This phenomenon was initially noted in population occupationally exposed to allergens and is related to the decrease in the prevalence of morbidities reported by workers (as compared to the general population) attributed to several employment-associated factors ${ }^{24,32-34}$. The "healthy worker effect" occurs because relatively healthy individuals are likely to gain employment and remain employed, while severely ill and chronically disabled individuals are ordinarily excluded from employment ${ }^{35,36}$. In our study, the admission policy was not known and data for workers that left their jobs due to health problems related with poultry 
production work were not obtained. All these data may contribute to a better explanation of the results obtained.

Regarding pharmacological therapy, all workers have prescribed drugs administered through inhalation devices that allow faster and more localized action ${ }^{1}$. In addition, this is the recommended route of administration for the treatment of asthma, since it allows greater therapeutic effectiveness and less systemic adverse reactions ${ }^{1}$. For allergic rhinitis and skin allergies, there were not registered any prescribed drugs, confirming the devaluation of these health conditions.

The asthmatic workers presented pharmacological therapy prescribed for the prevention and control of asthma attacks. In accordance with the guidelines, $28.6 \%$ asthmatics use a Short-acting $\beta_{2}$ Adrenergic Agonist (SABA) to control asthma attacks, since it is the first-line therapy in the control of bronchospasm ${ }^{10}$. In addition, there are asthmatics with glucocorticoids+LABA daily, which are also in accordance with the guidelines, since these drugs are first-line therapy in the prevention of asthma attacks in persistent asthma moderate to severe ${ }^{10}$. However, $85.7 \%$ asthmatics reported wheezing in association with dyspnea, resting dyspnea and persistent cough in the last year, suggesting an active asthma in need of adjustment in the prescribed pharmacological therapy ${ }^{10}$. Furthermore, some asthmatic workers do not take medication correctly, since are using glucocorticoids+LABA in the control of intermittent asthmatic crisis and/or LABA in monotherapy only in periods of higher exacerbation, which is not in line with the Global Initiative for Asthma ${ }^{10}$. According to the guidelines, SABA is the drugs recommended for the control of intermittent asthma attacks, because of their immediate bronchodilator effect. Glucocorticoids+LABA are not indicated for intermittent asthma attacks, since glucocorticoids are anti-inflammatory drugs with no bronchodilator effect and LABA despite being bronchodilators have a slow onset of action, and their administration in monotherapy is not recommended ${ }^{10}$. The incorrect use of the medication may contribute to the ineffectiveness of pharmacological therapy and, consequently, to the exacerbation of the disease ${ }^{10}$.

For asthmatic workers, the presence of asthma, dyspnea and/or wheezing was responsible for not attending the work. In addition, $4.5 \%$ workers reported having spent one night in the hospital last year, due to respiratory problems such as asthma, pulmonary infection, chronic obstructive pulmonary disease or sinusitis. The workers also reported episodes of chest tightness or wheezing in the course of their work and an improvement in respiratory complications during the weekend. These data suggest that swine and poultry farms may promote the continuous exposure to some triggering agents, like fungi and/or particulate matter, which cause harmful effects on its health ${ }^{1,2}$.

\section{Conclusions}

The professional activity in swine and poultry farms is associated with the development of respiratory and allergic symptoms. This study demonstrates that there is a prevalence of $5 \%$ of occupational asthma in this population. Furthermore, there is a high prevalence of asthma in swine than in poultry farmers; respiratory symptoms in asthmatic and non-asthmatic workers; symptoms of allergic rhinitis without diagnosis and skin allergies caused by occupational exposure. These data suggest that these farms develop activities that promote contact with harmful agents with influence on workers' health and their workers completely devalue the disease symptoms they present. This study also suggests that the prevalence of occupational asthma may be underestimated in these two settings, since nondiagnosed farmers with respiratory and allergic symptoms from occupational exposure were identified. The existence of non-asthmatic workers and without allergic rhinitis with respiratory and allergic symptoms may be a risk to developing some occupational allergic diseases, suggesting that occupational exposure is a possible responsible for the onset of an allergic pathology and associated symptomatology. These findings contribute to develop new policies in occupational health in order to the workers exposure to fungi, mycotoxins and/or particulate matter in Portuguese farms decreases the impact on their workrelated health effects. In this way, it becomes fundamental to use prevention strategies to reduce the exposure of workers, such as engineering controls (eg: ventilation, spraying of enclosed areas in order to prevent dust from rising, use of automatic feeding systems) and personal protective equipment (eg: gloves, masks and safety goggles) ${ }^{30,37}$. In addition, medical surveillance and awareness-raising actions are essential to promote the professional's education about occupational exposure, its effects on health and measures to minimize these effects ${ }^{38}$.

\section{Acknowledgments}

The authors are grateful to Autoridade para as Condicoes de Trabalho - ACT, Lisbon, Portugal, for funding the Project "Occupational exposure to fungi and particulate matter in poultry and swine" (n 049APJ/09). Carla Viegas also thanks to FCT - Fundacao para Ciencia e Tecnologia for funding the project EXPOsE - Establishing protocols to assess occupational exposure to microbiota in clinical settings (02/SAICT/2016 - Project $n^{\circ}$ 23222). H\&RTC authors gratefully acknowledge the FCT/MCTES national support through the UIDB/05608/2020 and UIDP/05608/2020. 


\section{Conflict of Interest}

None. I have full control of all primary data and permission is given to the journal to review the data if requested.

\section{References}

1. Radon K, Danuser B, Iversen M, et al. Respiratory symp toms in European animal farmers. Eur Respir J. 2001; 17(4):747-54. PMid: 11401073. https://doi.org/10.1183 /09031936.01.17407470

2. Radon $\mathrm{K}$, Weber $\mathrm{C}$, Iversen $\mathrm{M}$, et al. Exposure assessment and lung function in pig and poultry farmers. Occup Environ Med. 2001; 58:405-10. PMid: 11351057 PMCid: PMC1740142. https://doi. org/10.1136/oem.58.6.405

3. Donham K, Haglind P, Peterson Y, et al. Environmental and health studies of farm workers in Swedish swine confinement buildings. Br J Ind Med. 1989; 46(1):317. PMid: 2920141 PMCid: PMC1009719. https://doi. org/10.1136/oem.46.1.31

4. Zuskin E, Mustajbegovic J, Schachter E, et al. Respiratory function in poultry workers and pharmacologic chara cterization of poultry dust extract. Environ Res. 1995; 70(1):11-9. PMid: 8603653. https://doi.org/10.1006/ enrs.1995.1040

5. Larsson K, Eklund A, Malmberg P, et al. Alterations in bronchoalveolar lavage fluid but not in lung function and bronchial responsiveness in swine confinement workers. Chest. 1992; 101:767-74. PMid: 1541145. https://doi.org/10.1378/chest.101.3.767

6. Zejda JE, Hurst TS, Rhodes CS, et al. Respiratory health of swine producers: Focus on young workers. Chest. 1993; 103:702-9. PMid: 8449055. https://doi. org/10.1378/chest.103.3.702

7. Choudat D, Goehen M, Korobaeff M, et al. Respiratory symptoms and bronchial reactivity among pig and dairy farmers. Scand J Work Environ Health. 1994; 20:48-54. PMid: 8016599. https://doi.org/10.5271/ sjweh. 1429

8. Vogelzang PF, Van der Gulden JW, Tielen MJ, et al. Health-based selection for asthma, but not for chronic bronchitis in pigfarmers: An evidence-based hypothesis. Eur Respir J. 1999; 13:187-9. PMid: 10836346. https:// doi.org/10.1034/j.1399-3003.1999.13a34.x

9. Monso E, Riu E, Radon K, et al. Chronic obstructive pulmonary disease in never-smoking animal farmers working inside confinement buildings. Am J Ind Med, 2004; 46:357-62. PMid: 15376214. https://doi. org/10.1002/ajim.20077
10. Global Initiative for Asthma. Global strategy for asthma management and prevention (updated 2018). 2019. www.ginasthma.org/

11. Maestrelli P, Boschetto P, Fabbri L, et al. Mechanisms of occupational asthma. J Allergy Clin Immunol. 2009; 123(3):531-42. PMid: 19281901. https://doi. org/10.1016/j.jaci.2009.01.057

12. Kogevinas M, Anto J, Sunyer J, et al. Occupational asthma in Europe and other industrialized areas: A population based study. European Community Respi ratory Health Survey Study Group. Lancet. 1999; 353 (9166):1750-4. https://doi.org/10.1016/S0140-6736(9 8)07397-8

13. Bardana E. Occupational asthma and allergies. J Allergy Clin Immunol. 2003; 111:S530-9. PMid: 12592299. https://doi.org/10.1067/mai.2003.77

14. Holness DL, O'Blenis EL, Sass-Kortsak A, et al. Respiratory effects and dust exposures in hog confinement farming. Am J Ind Med. 1987; 11:571-80. PMid: 3591805. https://doi.org/10.1002/ ajim.4700110509

15. Vogelzang P, Van der Gulden J, Preller L, et al. Bronchial hyperresponsiveness and exposure in pig farmers. Int Arch Occup Environ Health. 1997; 70:327-33. PMid: 9352336. https://doi.org/10.1007/s004200050226

16. Kim K, Ko H, Kim Y, et al. Assessment of Korean farmer's exposure level to dust in pig buildings. Ann Agric Environ Med. 2008; 15:51-8.

17. Millner PD. Bioaerosols associated with animal production operations. Bioresour Technol. 2009; 100: 5379-85. PMid: 19395257.https://doi.org/10.1016/j.bio rtech.2009.03.026

18. Tsapko V, Chudnovets A, Sterenbogen M, et al. Exposure to bioaerosols in the selected agricultural facilities of the Ukraine and Poland - A review. Ann Agric Environ Med. 2011; 18:19-27.

19. Just N, Duchaine C, Singh B. An aerobiological perspective of dust in cagehoused and floor-housed poultry operations. J Occup Med Toxicol. 2009; 4:13. PMid: 19515256 PMCid: PMC2701955. https://doi. org/10.1186/1745-6673-4-13

20. Almeida A, Covas A, Prates L, et al. Internamento e mortalidade intra-hospitalar por asma em Portugal continental (2000-2007). Rev Port Pneumol. 2009; 15(3):367-83. https://doi.org/10.1016/S0873-2159(15) 30141-0

21. Sears M, Johnston N. Asthma exacerbations: Epide miology. Thorax. 2006; 61:722-8. PMid: 16877691 
PMCid: PMC2104697. https://doi.org/10.1136/thx.20 05.045161

22. Tantisira K, Colvin R, Tonascia J, et al. Airway responsiveness in mild to moderate childhood asthma: Sex influences on the natural history. Am J Respir Crit Care Med. 2008; 178(4):325-31. PMid: 18420965 PMCid: PMC2542438. https://doi.org/10.1164/rccm.2 00708-1174OC

23. Viegas S, Veiga L, Figueiredo P, et al. Occupational exposure to aflatoxin $\mathrm{B} 1$ in swine production and possible contamination sources. J Toxicol Environ Health A. 2013; 76(15):944-51. PMid: 24156697. https://doi.org/10.1080/15287394.2013.826569

24. Li CY, Sung EC. A review of the healthy worker effect in occupational epidemiology. Occup Med. 1999; 49:225-9. PMid: 10474913. https://doi.org/10.1093/ occmed/49.4.225

25. Viegas C, Carolino E, Malta-Vacas J, et al. Fungal contamination of poultry litter: A public health problem. J Toxicol Environ Health A. 2012; 75:134150. PMid: 23095152 . https://doi.org/10.1080/15287394 .2012 .721165

26. Viegas C, Carolino E, Sabino R, et al. Fungal contamination in swine: A potential occupational health threat. J Toxicol Environ Health A. 2013: 76(45):272-80. PMid: 23514069. https://doi.org/10.1080/15 287394.2013.757205

27. Thomson N, Chaudhuri R, Livingston E. Asthma and cigarette smoking. Eur Respir J. 2004; 24(5):822-33. PMid: 15516679. https://doi.org/10.1183/09031936.04 .00039004

28. Lazarus S, Chinchilli V, Rollings N, et al. Smoking affects response to inhaled corticosteroids or leukotriene receptor antagonists in asthma. Am J Respir Crit Care Med. 2007; 175(8):783-90. PMid: 17204725 PMCid: PMC1899291. https://doi.org/10.1164/rccm.2005111746OC

29. Brozek J, Bousquet J, Agache I, et al. Allergic Rhinitis and its Impact on Asthma (ARIA) guidelines - 2016 revision. J Allergy Clin Immunol. 2017; 140(4):950-8. PMid: 28602936. https://doi.org/10.1016/j.jaci.2017.03.050

30. Linaker C, Smedle J. Respiratory illness in agricultural workers. Occup Med. 2002; 52(8):451-9. PMid: 12488515. https://doi.org/10.1093/occmed/52.8.451
31. Valovirta E, Pawankar R. Survey on the impact of comorbid allergic rhinitis in patients with asthma. BMC Pulm Med. 2006; 6(1):S3. PMid: 17140421 PMCid: PMC1698496. https://doi.org/10.1186/14712466-6-S1-S3

32. Rimac D, Macan J, Varnai V, et al. Exposure to poultry dust and health effects in poultry workers: Impact of mould and mite allergens. Int Arch Occup Environ Health. 2010; 83:9-19. PMid: 19921239. https://doi. org/10.1007/s00420-009-0487-5

33. Burch JB, Svendsen E, Siegel PD, et al. Endotoxin exposure and inflammation markers among agricultural workers in Colorado and Nebraska. J Toxicol Environ Health A. 2010; 73:5-22. PMid: 19953416. https://doi. org/10.1080/15287390903248604

34. Burns CJ, Bodner KM, Jammer BL, et al. The healthy worker effect in US chemical industry workers. Occup Med. 2011; 61:40-4. PMid: 21078828. https://doi. org/10.1093/occmed/kqq168

35. Moual N, Kauffmann F, Eisen EA, et al. The healthy worker effect in asthma work may cause asthma, but asthma may also influence work. Am J Respir Crit Care Med. 2008; 177:4-10. PMid: 17872490 PMCid: PMC4767883. https://doi.org/10.1164/rccm.200703$415 \mathrm{PP}$

36. Thygesen LC, Hvidtfeldt UA, Mikkelsen S, et al. Quantification of the healthy worker effect: A nationwide cohort study among electricians in Denmark. BMC Public Health. 2011; 11:571. PMid: 21767353 PMCid: PMC3154868. https://doi.org/10.1186/1471-2458-11571

37. Dusser D, Montani D, Chanez P, et al. Mild asthma: An expert review on epidemiology, clinical characteristics and treatment recommendations. Allergy. 2007; 62:591-604. PMid: 17508962. https://doi.org/10.1111/ j.1398-9995.2007.01394.x

38. Mackiewicz B, Skorska C, Dutkiewicz J. Relationship between concentrations of microbiological agents in the air of agricultural settings and occurrence of workrelated symptoms in exposed persons. Ann Agric Environ Med. 2015; 22(3):473-7. PMid: 26403118. https://doi.org/10.5604/12321966.1167717 